\title{
Transient Hypothyroidism after Iodine-131 Therapy for Grave's Disease
}

\author{
Núria Gómez, José M. Gómez, Amat Orti, Laura Gavaldà, Carles Villabona, Pere Leyes and Joan Soler \\ Department of Endocrinology, Ciutat Sanitaria and University of Bellvitge, Barcelona, Spain
}

\begin{abstract}
We studied 355 patients with Grave's disease to characterize transient hypothyroidism and its prognostic value following ${ }^{131}$ therapy. Methods: The patients received therapeutic ${ }^{131}{ }^{1}$ treatment as follows: 333 received a dose $<10 \mathrm{mCi}(6.6 \pm 1.9 \mathrm{mCl})$ and 22 received a dose $>10 \mathrm{mCi}(12.8 \pm 2.9 \mathrm{mC})$. Diagnosis of transient hypothyroidism was based on low T4, regardless of TSH within the first year after ${ }^{131}$ I followed by recovery of T4 and normal TSH. Results: After administration of $<10 \mathrm{mCi}^{131} \mathrm{I}, 40$ patients developed transient hypothyroidism during the first year, transient hypothyroidism was symptomatic in 15. There was no transient hypothyroidism after high doses $\left(>10 \mathrm{mCl}\right.$ ) of ${ }^{131}$. lodine-131 uptake $>70 \%$ at $2 \mathrm{hr}$ before treatment was a risk factor for developing transient hypothyroidism (Odds ratio 2.8, 95\% confidence interval 0.9-9.4). At diagnosis of transient hypothyroidism, basal TSH levels were high (51\%), normal (35\%) or low (14\%); therefore, the transient hypothyroidism was not centralized. If hypothyroidism developed during the first 6 mo after basal TSH >45 mUMiter ruled out transient hypothyroidism. Conclusion: The development of transient hypothyroidism and its hormonal pattern did not influence long-term thyroid function. Since no prognostic factors reliably predicted transient hypothyroidism before ${ }^{131}$ I or at the time of diagnosis, if hypothyroidism appears within the first months after ${ }^{131}$, the reevaluation of thyroid function later is warranted to avoid unnecessary chronic replacement therapy.
\end{abstract}

Key Words: Grave's disease; iodine-131 therapy; transient hypothyroidism; permanent hypothyroidism

J Nuct Mod 1995; 36:1539-1542

\section{$\mathbf{S}_{\text {i }}$} long-term remission of Grave's disease, most patients with Grave's disease require definitive therapy with ${ }^{131} I$ or subtotal thyroidectomy. Iodine-131 is increasingly becoming the treatment of choice since it is effective and safe, but hypothyroidism is an unavoidable consequence which increases with time after treatment, especially after high dose therapy (1-3). Some patients, however, develop transient hypothyroidism within the first months after ${ }^{131} \mathrm{I}$ therapy (4). Although the diagnostic value of transient hypothyroidism is to avoid unnecessary chronic replacement ther-

Received May 3, 1994; revision accepled May 15, 1995.

For correspondence or repints contect: Núria Gómez Amak, MD, C/ Congost $30-324^{\circ} 5^{\circ}$, Barcolona 08024, Spain. apy, its incidence and characteristics are not well known (5). Recurrent as well as late permanent hypothyroidism have been described in patients with previous transient hypothyroidism (6), but no effective means to predict it are well known.

We undertook this study to: (a) characterize transient hypothyroidism after ${ }^{131}$ I therapy for Grave's disease, (b) seek predictive factors of transient hypothyroidism before ${ }^{131}$ I therapy, (c) differentiate transient hypothyroidism from permanent hypothyroidism at the time of diagnosis and (d) assess the predictive value of transient hypothyroidism in long-term thyroid function.

\section{MATERIALS AND METHODS}

\section{Patients}

From 1979 to 1991,372 patients underwent therapeutic ${ }^{131} I$ treatment for Grave's disease. Due to insufficient data from follow-up, 17 patients were excluded from the analysis. Thus, we report on 355 patients.

Diagnosis of Grave's disease was based on clinical features, subnormal serum concentration of thyrotropin (TSH) with concomitant increase in thyroxine (T4) or triiodothyronine levels (T3) or both. Diffuse goiter was assessed scintigraphically.

The patients (333) were treated with calculated low doses of ${ }^{131}$ I lower than $10 \mathrm{mCi}(6.6 \pm 1.9 \mathrm{mCi})$ determined by gland weight and ${ }^{131} \mathrm{I}$ uptake at 2 and $24 \mathrm{hr}$. The remaining 22 patients were treated with a dose higher than $10 \mathrm{mCi}(12.8 \pm 2.9 \mathrm{mCi})$ because of severe associated illness and/or persistent hyperthyroidism after low dose administration.

Two hundred and seven patients (58\%) were treated with antithyroid drugs for a minimum of $6 \mathrm{mo}$ and 13 patients underwent subtotal thyroidectomy as the first therapeutic option before ${ }^{131}$ I treatment. No patient received antithyroid drugs after ${ }^{131}$ I therapy.

\section{Follow-up}

Clinical examination and T4, T3 and basal TSH measurements were performed at monthly intervals during the first $6 \mathrm{mo}$, at 12 mo and then yearly until permanent hypothyroidism developed. The mean follow-up period was 34.3 mo (range 12-145).

Within the first 6 mo after ${ }^{131} \mathrm{I}$ therapy, hypothyroidism was diagnosed by low T4 levels regardless of TSH levels, with or without hypothyroid symptoms. If $\mathrm{T} 4$ levels later became normal and the basal TSH levels were lower than $8 \mathrm{mU} / \mathrm{iter}$, the diagnosis transient hypothyroidism, but when TSH levels were higher than $8 \mathrm{mU} /$ iter, the diagnosis was permanent hypothyroidism (7). In the first $6 \mathrm{mo}$, transient thyroxine replacement was started in asymptomatic patients and withdrawn before the next therapeutic 
course. Patients whose hyperthyroidism relapsed were treated with an additional ${ }^{131}$ I dose.

\section{Measurements}

Total serum T4 (normal values $70-170$ nmole/liter), T3 (normal values 1.2-3 nmole/liter) and TSH (normal values 0.1-4 mU/hiter) were measured by specific radioimmunoassays. From 1986, hormone levels were determined by enzymoimmunoassay.

Thyroid uptake of ${ }^{131} \mathrm{I}$ at 2 and $24 \mathrm{hr}$ was calculated from a $50-\mathrm{mCi}$ tracer dose given before the therapeutic dose.

\section{Data Analysis}

We analyzed the following variables: sex, age, previous antithyroid drug intake and surgical treatment, ${ }^{131} I$ uptake at 2 and 24 hr, T4 and T3 levels before ${ }^{131}$ I therapy, ${ }^{131}$ I to dose-induced transient hypothyroidism, the ${ }^{131} \mathrm{I}$ accumulative dose (in $\mathrm{mCi}$ ) and T4, T3 and basal TSH levels during transient hypothyroidism. Data were expressed as mean \pm s.d. Variables were compared by chi square testing and analysis of variance (SPSS program) (8).

Survival analysis of disease by the Kaplan-Meier method (9) was performed and time-dependent variables analyzed by the Mantel-Cox method (BMDP1L program) to describe the time course of thyroid function after ${ }^{131}$ I therapy $(10,11)$. Patients who developed permanent hypothyroidism during the first 6 mo after ${ }^{131}$ I therapy were exluded from life-table analysis because it is not possible that transient hypothyroidism developed during the same period. To predict risk factors for developing transient hypothyroidism, patients were distributed into categories of exposure for each variable, and the Odds ratio was estimated with a multivariate statistical model by conditional logistic regression using the likelihood ratio method (EGRET program).

\section{RESULTS}

Of the 333 patients treated with calculated low doses of ${ }^{131} \mathrm{I}$, transient hypothyroidism was diagnosed in 40 (29 women, 11 men, aged $28-71$ yr; mean, 48.8 yr). Twenty-six patients developed transient hypothyroidism after the first dose of ${ }^{131} \mathrm{I}$, nine after the second and two after the third. Three patients developed transient hypothyroidism twice (two patients after the first and second ${ }^{131} I$ doses and a third after the second and fourth ${ }^{131}$ I doses), making the total number of transient hypothyroidism episodes 43 . Transient hypothyroidism was not diagnosed after high dose therapy. No differences were observed in clinical and laboratory findings at the time of ${ }^{131} I$ therapy or in thyroid function after ${ }^{131} I$ administration between patients treated with low and high doses (data not shown).

Patients with and without transient hypothyroidism were compared to predict the development of transient hypothyroidism (Table 1). Pretreatment T4 and T3 levels and ${ }^{131} \mathrm{I}$ uptake at $2 \mathrm{hr}$ postadministration were higher in the transient hypothyroidism group. After multivariate statistical analysis, only ${ }^{131} \mathrm{I}$ uptake higher than $70 \%$ at $2 \mathrm{hr}$ was a significant risk factor for developing transient hypothyroidism (Odds ratio 2.8, confidence interval 0.9-9.4), with a positive predictive value of $28.1 \%$ and a negative predictive value of $89.7 \%$.

The time of diagnosis of transient hypothyroidism was $2.1 \pm 1$ mo after ${ }^{131} \mathrm{I}$ (range 1-6 mo). Recovery of thyroid function was delayed $3 \pm 1.1 \mathrm{mo}$ (range $1-5 \mathrm{mo}$ ).
TABLE 1

Clinical and Laboratory Findings in Patients According to Development of Transient Hypothyroidism (TH) at the Time of lodine-131 Therapy*

\begin{tabular}{lccc}
\hline \multicolumn{1}{c}{ Variable } & TH & No TH & $\mathrm{p}^{*}$ \\
\hline $\begin{array}{l}\text { No of patients } \\
\text { Sex }\end{array}$ & 40 & 293 & \\
$\quad$ Male & $11(27.5 \%)$ & $77(26.3 \%)$ & $\mathrm{ns}$ \\
$\quad$ Female & $29(72.5 \%)$ & $216(77.3 \%)$ & $\mathrm{ns}$ \\
Age & $49 \pm 12$ & $51 \pm 11$ & $\mathrm{~ns}$ \\
Previous antithyroid & $16(40 \%)$ & $123(41.9 \%)$ & $\mathrm{ns}$ \\
$\quad$ drug treatment & & & \\
Previous surgery & 0 & $13(4.4 \%)$ & $\mathrm{ns}$ \\
T4 (nmole/iter) & $277 \pm 67$ & $245 \pm 60$ & 0.001 \\
T3 (nmole/iter) & $6.4 \pm 1.9$ & $5.4 \pm 2.2$ & 0.004 \\
131 I uptake at 2 $\mathrm{hr}(\%)$ & $53 \pm 21$ & $44 \pm 20$ & 0.009 \\
131/ uptake at 24 hr (\%) & $54 \pm 17$ & $60 \pm 17$ & $\mathrm{~ns}$ \\
Initial dose (mCi) & $6.9 \pm 1.9$ & $6.5 \pm 1.9$ & $\mathrm{~ns}$ \\
Total dose (mCi) & $10.6 \pm 6.3$ & $8.4 \pm 4.6$ & 0.008 \\
\end{tabular}

"All values are expressed as mean \pm s.d. for continuous variables and as the percentage (number in parentheses) for categorical variables.

The hormonal pattern at the time of transient hypothyroidism diagnosis was: low T4 in all 40 patients, low T3 in 29, high basal TSH in 22, normal TSH in 15 and low TSH in 6 ( $<0.1 \mathrm{mU} /$ liter) (Fig. 1). No variable correlated with the hormonal pattern or transient hypothyroidism duration (data not shown).

Hypothyroid symptoms were present in 15 patients $(37.5 \%)$ and thyroxine replacement was started (mean duration, $2.4 \mathrm{mo}$; range, 1-4 mo).

To differentiate transient hypothyroidism from permanent hypothyroidism, patients who developed permanent hypothyroidism during the first 6 mo after ${ }^{131}$ I were compared with transient hypothyroidism patients (Table 2). No patient with basal TSH higher than $45 \mathrm{mU} /$ liter had transient hypothyroidism. Therefore, TSH levels higher than $45 \mathrm{mU} /$ liter had a $100 \%$ positive predictive value for permanent hypothyroidism in the first months after ${ }^{131} I$ treatment.

At the 12th mo, 34 patients with transient hypothyroidism were euthyroid and only two of these had TSH levels

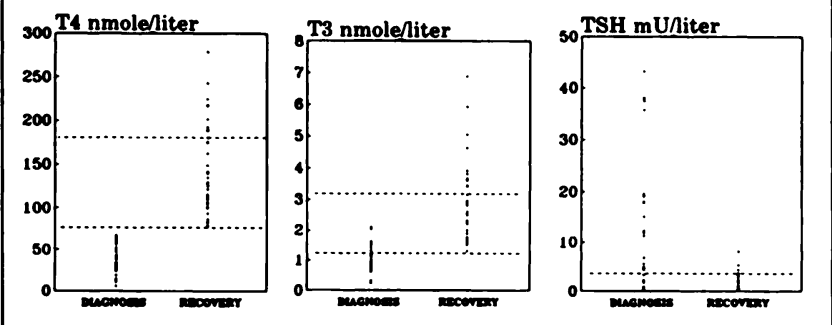

FIGURE 1. T4, T3 and TSH levels at diagnosis of transient hypothyroidism and at the time of recovery of thyroid function. The horizontal dashed line represents the normal range of T4 (70-160 nmole/iter), T3 (1.2-3 nmole/liter) and the upper limit range of basal TSH (0.1-4 mU/iter). 
TABLE 2

Clinical and Laboratory Findings

\begin{tabular}{|c|c|c|c|}
\hline Variable & TH & PH & $\mathbf{p}^{*}$ \\
\hline No. of patients & 40 & 110 & \\
\hline \multicolumn{4}{|l|}{ Sex } \\
\hline Male & $11(27.5 \%)$ & 31 (28.2\%) & ns \\
\hline Female & $29(72.5 \%)$ & $79(71.8 \%)$ & ns \\
\hline Age & $49 \pm 12$ & $50 \pm 11$ & ns \\
\hline $\begin{array}{l}\text { Previous antithyroid drug } \\
\text { treatment }\end{array}$ & $16(40 \%)$ & $55(50 \%)$ & ns \\
\hline Previous surgery & 0 & $3(2.7 \%)$ & ns \\
\hline Pretreatment T4 (nmole/iter) & $277 \pm 67$ & $245 \pm 57$ & 0.003 \\
\hline Pretreatment T3 (nmoleniter) & $6.4 \pm 1.9$ & $5.3 \pm 2.1$ & 0.003 \\
\hline 131 / uptake at $2 \mathrm{hr}(\%)$ & $53 \pm 21$ & $42 \pm 19$ & 0.003 \\
\hline 131/ uptake at $24 \mathrm{hr}(\%)$ & $54 \pm 17$ & $59 \pm 17$ & ns \\
\hline Initial dose (mCi) & $6.9 \pm 1.9$ & $6.3 \pm 1.9$ & ns \\
\hline Total dose (mCi) & $10.6 \pm 6.3$ & $7.9 \pm 4.1$ & 0.002 \\
\hline $\begin{array}{l}\text { T4 at diagnosis of } \\
\text { hypothyroidism } \\
\text { (nmole/iter) }\end{array}$ & $41 \pm 18$ & $36 \pm 23$ & ns \\
\hline $\begin{array}{l}\text { T3 at diagnosis of } \\
\text { hypothyroidism } \\
\text { (nmolenliter) }\end{array}$ & $1.1 \pm 0.4$ & $1.1 \pm 0.6$ & ns \\
\hline $\begin{array}{l}\text { Basal TSH at diagnosis of } \\
\text { hypothyroidism (mU/iter) }\end{array}$ & $13.3 \pm 10.6$ & $44.9 \pm 33.9$ & 0.001 \\
\hline
\end{tabular}

*According to development of transient (TH) or permanent (PH) hypothyroidism in the first 6 mo after ${ }^{131}$ I Therapy

*All values are expressed as mean \pm s.d. for continuous variables and as the percentage (numbers in parentheses) for categorical variables.

between 4 and $8 \mathrm{mU} /$ iter which had normalized in the next treatment course with no thyroxine replacement. In the remaining six patients, hyperthyroidism relapsed during the first 6 mo after transient hypothyroidism diagnosis. No differences were observed during ${ }^{131} \mathrm{I}$ therapy or transient hypothyroidism between patients who relapsed and those who became euthyroid after diagnosis of transient hypothyroidism (data not shown).

Life-table analysis showed an $81.4 \%$ risk of permanent hypothyroidism 141 mo after ${ }^{131}$ I therapy for patients who previously developed transient hypothyroidism versus 89.9\% for patients without transient hypothyroidism $(p=0.64)$ (Fig. 2). TSH levels at the onset and end of transient hypothyroidism did not correlate with the probability of late-onset permanent hypothyroidism $(p=0.53$ ).

\section{DISCUSSION}

The incidence of transient hypothyroidism in patients treated with low-dose radioiodine was $12.1 \%$ and has been reported to range from $3.8 \%$ to $28 \%(5,6,12-16)$. These variations may result not only from differences in follow-up and the administered ${ }^{131}$ I dose but also from the imprecise definition of transient hypothyroidism in many reports. Our series included patients diagnosed with transient hypothyroidism if T4 levels were low, regardless of basal TSH in the first months after ${ }^{131}$ I therapy, followed by T4 level normalization and serum TSH levels lower than 8

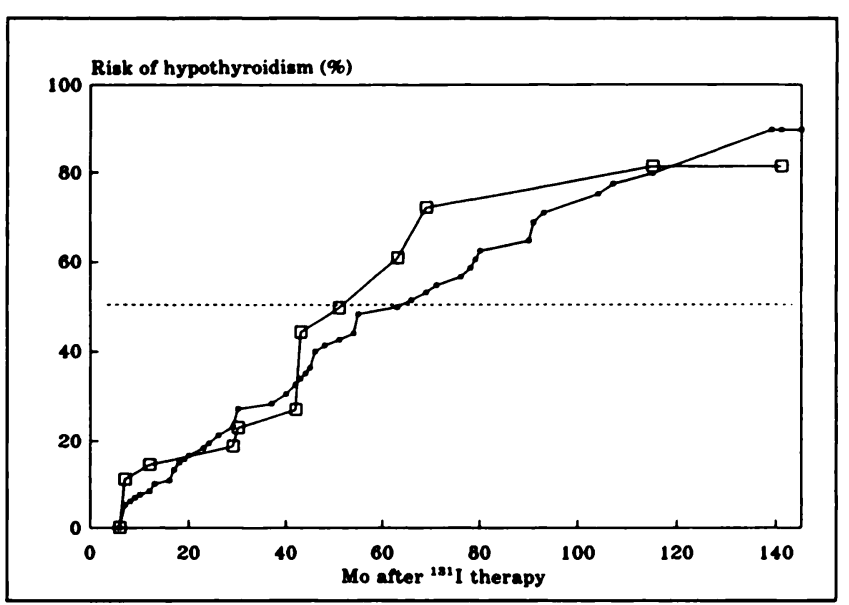

FIGURE 2. Risk of permanent hypothyroidism by the KaplanMeier estimation according to the development of transient hypothyroidism. The horizontal dashed line represents the median probability of permanent hypothyroidism.

mU/liter during the next few months. TSH levels at the time of the transient hypothyroidism diagnosis were excluded from diagnostic criteria because of the slow recovery of TSH secretion after long-term suppression in thyrotoxic patients $(4,17-20)$. We found that transient hypothyroidism developed within the first 6 mo and disappeared within the first year after ${ }^{131}$ I therapy. Patients with basal TSH levels between 4 and $8 \mathrm{mU} / \mathrm{liter}$ after recovery of peripheral thyroid function were included in the analysis since these levels normalized spontaneously. In contrast, patients with high basal TSH levels who were treated with ${ }^{131}$ I should be considered as having permanent hypothyroidism $(4-6,14,16,19)$.

Transient hypothyroidism did not develop in those patients with Grave's disease who received ${ }^{131}$ I doses greater than $10 \mathrm{mCi}$. This factor may be related to the small number of patients included in this group $(n=22)$; however, transient hypothyroidism has not been described in patients who received high doses of ${ }^{131} I(1-3)$.

After multivariate statistical analysis, the only significant risk factor for developing transient hypothyroidism was ${ }^{131}$ I uptake at $2 \mathrm{hr}$ higher than $70 \%$ before therapy. This should be considered a negative risk factor because of the low positive predictive value $(28.1 \%)$ and high negative predictive value $(89.7 \%)$.

The main problem in clinical practice is to differentiate transient hypothyroidism from permanent hypothyroidism in the early months after therapy. We found that TSH levels higher than $45 \mathrm{mU} /$ iter were a predictive factor for permanent hypothyroidism, with a specificity of $100 \%$.

According to some authors, transient hypothyroidism is a central hypothyroidism phase during recovery of the hypothalamic-pituitary axis after ${ }^{131}$ I treatment (21). Our results do not support this hypothesis since basal TSH levels were high $(51 \%)$, normal $(35 \%)$ or low $(14 \%)$ at the onset of transient hypothyroidism and the time of recovery of thyroid function did not correlate with initial TSH levels. 
Moreover, transient hypothyroidism is not present in other hyperthyroidal etiologies with proven pituitary suppression after therapy (22). In contrast, other authors suggest that previous treatment with antithyroid drugs may induce intrathyroidal iodine depletion and, after ${ }^{131}$ I therapy, a reduction in the entrapment of iodine by the gland may impair the maintenance of thyroid hormone production (23). In our study, antithyroid pretreatment was not associated with development of transient hypothyroidism. Finally, transient hypothyroidism may be immunomediated by TSH receptor antibodies, which may account for the specificity of transient hypothyroidism in Grave's disease. Thus, ${ }^{131}$ I therapy would cause diffuse thyroid damage and a simultaneous rise in thyrotropin receptor antibodies (24-27), which may be blockers. This analysis was not possible in our series because many of the patients did not have these antibodies. The outcome for patients with transient hypothyroidism is not well known $(5,6,16)$. Recurrent hyperthyroidism has been described $(6,16)$ and was also diagnosed in six of our patients. Analysis by the MantelCox method showed that residual thyroid function did not differ from that of patients without previous transient hypothyroidism and was independent of TSH levels during transient hypothyroidism.

\section{CONCLUSION}

Transient hypothyroidism developed in $12.1 \%$ of patients treated with low-dose ${ }^{131}$ I for Grave's disease during the first year after ${ }^{131}$ I therapy and was asymptomatic in most patients. Transient hypothyroidism did not develop after administration of doses higher than $10 \mathrm{mCi}$. Transient hypothyroidism was not a central hypothyroidism since TSH levels were high, normal or low at transient hypothyroidism onset and did not correlate with the time of recovery. There was no prognostic factor to reliably predict transient hypothyroidism before ${ }^{131}$ I therapy or at the time of diagnosis. TSH levels higher than $45 \mathrm{mU} /$ iter ruled out transient hypothyroidism. In view of our findings, the possibility of spontaneous recovery of thyroid function should be considered before making a diagnosis of definitive hypothyroidism within the first months after ${ }^{131}$ I therapy, particularly if TSH levels are lower than $45 \mathrm{mU} / \mathrm{iter}$. Consequently, we recommend later assessment of thyroid function, for example, 6 mo after ${ }^{131}$ I therapy, because at that time all of our patients with transient hypothyroidism had recovered their thyroid function. Although transient hypothyroidism was not a prognostic index future thyroid function, its clinical significance lies in accurate diagnosis to avoid chronic thyroxine replacement.

\section{ACKNOWLDGMENT}

The authors thank Mrs. Cristine O'Hara for her editorial services.

\section{REFERENCES}

1. Kendall-Taylor P, Keir MJ, Ross WM. Ablative radioiodine therapy for hyperthyroidism. Br Med J 1984;289:361-363.
2. Eriksson E, Ericksson $K$, Wahlberg $P$. Treatment of hyperthyroidism with standard doses of radioiodine aiming at ablation. Acta Med Scand 1985;217: 55-60.

3. Ratcliffe GE, Fogelman I, Maisey MN. The evaluation of radioiodine therapy for thyroid patients using a fixed dose regime. Br J Radiol 1986;59: 1105-1107.

4. Toft AD, Irvine WJ, Hunter WM, Ratcliffe JG, Seth J. Anomalous plasma TSH levels in patients developing hypothyroidism in the early months after ${ }^{131}$ I therapy for thyrotoxicosis. J Clin Endocrinol Metab 1974;39:607-609.

5. Sawers JSA, Toft AD, Irvine WJ, Brown NS, Seth J. Transient hypothyroidism after ${ }^{131}$ I treatment of thyrotoxicosis. J Clin Endocrinol Metab 1980;50:226-229.

6. Virgili N, Gómez JM, Montaña E, Soler J, Castells M, Roca M. Evolución a corto plazo de la enfermedad de Graves-Basedow tratada con ${ }^{131}$ I. Prevalencia del hipotiroidismo transitorio. Rev Clin Esp 1988;183:300-303.

7. Shalet SM, MacFarlane IA, Beardwell CG. Patient at risk of hypothyroidism. Lancet 1977;2:1356-1357.

8. Rosner B. Fundamentals of biostatistics. Duxbury Press. Boston; 1986: 326-332.

9. Kaplan EL, Meier P. Nonparametric estimation from incomplete observations. J Am Stat Assoc 1958;53:457-481.

10. Dixon WJ. BMDP statistical software. Berkeley University of California Press, 1985.

11. Mantel N. Evaluation of survival data and two new rank order statistics arising and its consideration. Cancer Chemother Rep 1966;50:163-170.

12. Fraser R, Abbatt JD, Stewart FS. Radioiodine treatment of thyrotoxicosis. A single dose method following a drug preparation. Br J Radiol 1954;27:2326.

13. Connell JMC, Hiblitch TE, Mc Cruden DC, Alexander WD. Transient hypothyroidism following radioiodine therapy for thyrotoxicosis. $\mathrm{Br} J \mathrm{Ra}$ diol 1983;56:309-313.

14. Dorfman SG, Young RL, Carretta RF. Transient hypothyroidism. Arch Intem Med 1977;137:256-257.

15. Peden NR, Hart IR. The early development of transient and permanent hypothyroidism following radioiodine therapy for hyperthyroid Grave's disease. Can Med Ass J 1984;130:1141-1144.

16. MacFarlane IA, Shalet SM, Beardwell CG, Khara JS. Transient hypothyroidism after ${ }^{131}$ I treatment of thyrotoxicosis. Br Med J 1979;2:421-422.

17. Lucas T, Martin Zurro A, Roca M, et al. Tratamiento de la enfermedad de Basedow con ${ }^{131}$ I. Incidencia de hipotiroidismo transitorio. Endocrinologta 1982;29:11-15.

18. Gordin A, Wagar G, Hernberg CA. Serum thyrotropin and response to TRH in patients who are euthyroid after radioiodine treatment for hyperthyroidism. Acta Med Scand 1973;194:335-340.

19. Vageankis AG, Bravermann LE, Azizi F, Portmay GI, Ingbar SH. Recovery of pituitary thyrotropic function after withdrawal for prolonged thyroid suppression therapy. N Engl J Med 1978;293:681-684.

20. Bellabarba D, Benard B, Langlois M. Pattern of serum thyroxine, triiodothyronine and thyrotropin after treatment of thyrotoxicosis. Clin Endocrinol (Oxf) 1972;1:345-349.

21. Sánchez-Franco F, Garcia MD, Martin-Zurro A, et al. Transient lack of thyrotropin (TSH) response to thyrotropin-releasing hormone (TRH) in treated hyperthyroid patients with normal or low serum thyroxine (T4) and triiodothyronine (T3). J Clin Endocrinol Metab 1974;38:1098-1102.

22. Uy HL, Reasner CA, Samuels MH. Pattern of recovery of the hypothalamic-pituitary-thyroid axis following radioactive iodine ablation therapy in patients with Grave's disease [Abstract]. 75th Congress Endocr Soc 1993; 460.

23. Gómez JM, Virgili N, Soler J, Fernandez M, Montaña E. Transient hypothyroidism after iodine-131 treatment of Grave's disease. Thyroidd Clin Exp 1989;3:149-152.

24. Harden RM, Alexander WD, Koutran DA, Harrison MT, Wayne E. Quantitative measurement of iodine metabolism after long-term treatment for thyrotoxicosis with antithyroid drugs. J Clin Endocrinol Metab 1966;26: 397-401.

25. Atkinson S, McGregor AM, Kendall-Taylor P, Peterson MM, Smith BR. Effect of radioiodine on stimulatory activity of Grave's immunoglobulins Clin Endocrinol (Oxf) 1982;6:537-541.

26. Cho BY, Shong YK, Chung JK, et al. Changes in the properties of the thyrotropin receptor antibody in patients with Grave's disease after radioiodine treatment. Kor J Intern Med 1990;5:51-57.

27. Kaise K, Kaise N, Yoshida K, et al. Thyrotropin receptor antibody activities significantly correlate with the outcome of radioiodine $\left({ }^{131} \mathrm{I}\right)$ therapy for hyperthyroid Grave's disease. Endocrinol Jpn 1991;38:429-33. 